\title{
Costs of excessive postoperative hemorrhage in cardiac surgery
}

\author{
Michael C. Christensen, MSc, MPA, DrPH, ${ }^{\mathrm{a}}$ Stephan Krapf, MD, ${ }^{\mathrm{b}}$ Angela Kempel, MSc, ${ }^{\mathrm{c}}$ and \\ Christian von Heymann, MD, PhD, DEAA ${ }^{\mathrm{d}}$
}

Background: Excessive postoperative hemorrhage in cardiac surgery is a serious clinical complication placing substantial demands on hospital resources. This study quantifies the exact impact of postoperative hemorrhage on hospital costs in Germany.

\begin{abstract}
Methods: We retrospectively analyzed data collected prospectively in the Quality Assurance Database at the Heart Center of the Klinikum Augsburg, Germany. All relevant perioperative data for resources consumption were analyzed and compared in patients with and without excessive postoperative hemorrhage in cardiac surgery. Multivariate regression analysis identified the incremental costs of postoperative hemorrhage while adjusting for potential confounding.
\end{abstract}

Results: A total of 1118 patients had cardiac surgery between January and December 2006. Six percent were identified with excessive postoperative hemorrhage. The risk of experiencing a postoperative complication (including death) $(P<.0001)$, returning to operating room for reexploration $(P<.0001)$, staying in intensive care unit for longer than 72 hours $(P<.0001)$, receiving ventilation for longer than 24 hours $(P<.0001)$, and receiving any kind of postoperative blood transfusion $(P<.0001)$ was significantly higher in patients with excessive postoperative hemorrhage. Twenty-two percent of patients with excessive postoperative hemorrhage died compared with $6 \%$ of the patients without excessive postoperative hemorrhage $(P<.0001)$. When adjusting for potential confounding factors, the incremental costs of excessive postoperative hemorrhage was $€ 6251$ (95\% confidence interval, 4594-7909).

Conclusions: The average hospital costs related to excessive postoperative hemorrhage in cardiac surgery in Germany are substantial and associated with a significant risk of postoperative complications and death. Clinical interventions that can effectively prevent or address excessive postoperative hemorrhage in cardiac surgery are likely to have substantial cost-effectiveness potential.

Excessive postoperative hemorrhage in cardiac surgery is a serious complication that is independently associated with serious postoperative adverse events, including sepsis, acute respiratory distress syndrome, renal failure, and death. ${ }^{1-5} \mathrm{Ex}-$ cessive postoperative hemorrhage and its associated risk of reexploration also place a high demand on hospital resources in terms of transfusion needs, ventilatory support requirements, intensive care support, and manpower requirements. ${ }^{5-9}$ No standard definition of excessive postoperative hemorrhage exists, ${ }^{10}$ and there is a lack of solid incidence data as a result, yet reports in the literature indicate that $3 \%$ to $5 \%$ of patients undergoing cardiac surgery require a second operation to control postoperative hemorrhage. ${ }^{3,4,9,11}$

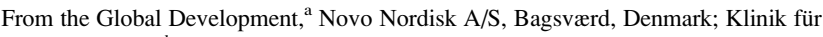
Herzchirurgie, ${ }^{b}$ Herzzentrum Augsburg, Augsburg, Germany; Pharmametrics $\mathrm{GmbH},{ }^{\mathrm{c}}$ Institute for Health Economics \& Epidemiology, Freiburg, Germany; and Department of Anaesthesiology and Intensive Care Medicine, ${ }^{\mathrm{d}}$ Charité-University Medicine Berlin, Campus Virchow-Klinikum, Berlin, Germany.

Received for publication March 17, 2008; revisions received Sept 12, 2008; accepted for publication Feb 2, 2009; available ahead of print April 20, 2009.

Address for reprints: Michael C. Christensen, MSc, MPA, DrPH, Global Development, Novo Nordisk A/S, Krogshoejvej 55, 2880 Bagsvaerd, Denmark (E-mail: mcrc@novonordisk.com).

J Thorac Cardiovasc Surg 2009;138:687-93

$0022-5223 / \$ 36.00$

Copyright (c) 2009 by The American Association for Thoracic Surgery

doi:10.1016/j.jtcvs.2009.02.021
}

Despite the substantial toll on hospital resources, little is in fact known about the exact economic impact of this complication. To our knowledge, only one group of researchers has examined the cost of postoperative hemorrhage in cardiac surgery. ${ }^{7,8}$ In these small case-control US studies, patients with postoperative hemorrhage required significantly more blood transfusion and longer intensive care unit (ICU) and hospital stay. The mean incremental costs of excessive postoperative hemorrhage, defined as postoperative chest tube drainage greater than $800 \mathrm{~mL}$ during a 4-hour period, was $\$ 11,266$. $^{8}$

Knowledge of the economic consequences of excessive postoperative hemorrhage is a highly essential step in the efforts to identify potentially cost-effective clinical interventions in cardiac surgery. Avoidance of postoperative hemorrhage may reduce morbidity and mortality and reduce the requirements for hospital resources. ${ }^{12,13}$ Depending on their costs, new clinical interventions can either be cost-saving (if hospital costs savings are greater than the cost of the intervention), cost-effective (if the incremental costs of using the clinical intervention is reasonable in regards to the clinical benefits obtained), or cost-enhancing (if the clinical intervention induces higher hospital costs without any clinical benefit). By quantifying the economic consequences of excessive postoperative hemorrhage, it is possible to evaluate the cost-effectiveness of clinical interventions to avoid excessive hemorrhage and hopefully optimize the clinical pathway and outcome. 


$$
\begin{aligned}
& \text { Abbreviations and Acronyms } \\
& \begin{aligned}
\text { AMI } & \text { acute myocardial infarction } \\
\text { CPB } & =\text { cardiopulmonary bypass } \\
\text { ICU }= & \text { intensive care unit } \\
\text { TISS-28 } & =\text { Therapeutic Intervention Scoring } \\
& \text { System }
\end{aligned}
\end{aligned}
$$

The objective of this study is to quantify the incremental average hospital costs of excessive postoperative hemorrhage in cardiac surgery in Germany.

\section{METHODS \\ Definition of Excessive Postoperative Hemorrhage}

We defined excessive postoperative hemorrhage as postoperative bleeding into drains placed in the cardiothoracic cavity after admission to the ICU. Drainage loss was assessed on an hourly basis after completion of a 30-minute stabilization period. Drainage loss was defined by at least 1 of the following criteria: (1) $\geq 200 \mathrm{~mL} / \mathrm{h}$ in any 1 hour or part thereof, or (2) $\geq 2 \mathrm{~mL} / \mathrm{kg} / \mathrm{h}$ for 2 consecutive hours in the first 6 hours after surgery. Blood loss during the stabilization period was not included in the definition of the volume criteria as such loss may be due to postural changes when transferring the patient from the operating room table to the bed or due to fluid in the pleural or mediastinal cavity, which may have arisen from the rinsing with water as an attempt to achieve surgical hemostasis. Information on hourly bleeding was manually extracted from patient records.

\section{Study Population}

The Quality Assurance Database in Germany was established in 2001 to enhance the quality of all surgical interventions performed in the country. All cardiac surgery units submit annually a standard set of perioperative data related to all cardiac surgeries performed. In this study, we obtained data for all patients aged $18+$ having cardiac surgery at the Heart Center of the Klinikum Augsburg between January 1, 2006 and December 31, 2006. A total of 1233 patients had cardiac surgery with cardiopulmonary bypass (CPB) at this hospital that year, and after adjusting for inconsistent data, 1188 patients were eligible to be included in the study. The Institutional Review Board at Klinikum Augsburg approved the study (IRB No. 45033).

\section{Data Collection and Cost Assessment}

All relevant data on patient characteristics, surgical care, postoperative care, and clinical outcomes were collected. All postoperative complications identified were defined according the National Bundesgeschäftsstelle Qualitätssicherung $\mathrm{gGmbH}$ definitions ${ }^{14}$ as the Quality Assurance database at Klinikum Augsburg follows the exact same data structure as the national Bundesgeschäftsstelle Qualitätssicherung gGmbH database. We calculated treatment costs for each patient according to resources consumed during surgery, resources consumed in ICU, and resources consumed in general ward before hospital discharge. Specifically, we investigated costs by type of surgery, surgery time, need and time for hemofiltration, intra-aortic balloon pump, and extracorporeal membrane oxygenation, incidence of reexploration for bleeding and other causes, blood transfusion (all types of products), admission and length of stay in ICU, ventilatory support requirements, manpower requirements in ICU as measured by the Therapeutic Intervention Scoring System (TISS-28) score, and length of stay in hospital after discharge from ICU. Data on unit costs were obtained for all relevant resource use (Appendix 1). Treatment costs were determined on a patientlevel basis by multiplying the individual resource use with the relevant unit costs. Overhead costs were not specifically accounted for in this anal- ysis, yet they were captured in the cost for ICU and general ward stay (cost per day).

\section{Statistical Analysis}

First, we examined the demographic and clinical characteristics (pre- and postoperative) of the study population and the acute treatment provided in the total cohort and separately in patients with and without postoperative hemorrhage. Noncontinuous variables were compared using the chi-square test or Fisher exact test, as appropriate. Continuous variables were described by the mean \pm standard deviation. The Mann-Whitney rank-sum test was used to compare medians where a normality test failed. Second, we computed treatment costs for every patient and calculated average treatment costs for the total study population. The average costs of treatment was analyzed according to the main components of care and the unadjusted differences in costs between patients with and without excessive postoperative hemorrhage were analyzed. Third, to identify the incremental costs of excessive postoperative hemorrhage while adjusting for potential confounding factors, we undertook a multivariate regression analysis using ordinary least squares. We adjusted for all pre- and intraoperative characteristics that potentially could explain differences in treatment costs between patients with and without excessive postoperative hemorrhage. All statistical analyses were performed using LimDep Software, Version 3.0.5, 2003.

\section{RESULTS}

Of the 1188 patients with complete data, $57.2 \%$ had primary coronary artery bypass grafting surgery; $18.3 \%$, single valve surgery (repair or replacement); $22 \%$, both types of surgeries; and $2.5 \%$, other types of major cardiac surgery, including aortic root replacement. A total of 76 patients $(6.4 \%)$ were identified with excessive postoperative hemorrhage after applying the criteria for hemorrhage in the ICU. The preoperative characteristics of patients are shown in Table 1. Seventy-two percent $(n=865)$ of the patients were men, and the mean age was 67 years $( \pm 11)$. Forty-nine percent were admitted with a primary diagnosis of acute myocardial infarction (AMI), and $24 \%$ were admitted with valve disorder. Patient with excessive postoperative hemorrhage were significantly more likely to have preoperative renal dysfunction $(P=.0229)$, liver disease $(P=.0458)$, preoperative coagulopathy $(P=.0207)$, and emergency surgery $(P=.0416)$. Duration of surgery $(P=.0012)$ and time on CPB $(P=$ $.0015)$ were also significantly longer in patients with excessive postoperative hemorrhage (Table 2), and they were significantly more likely to require hemofiltration $(P=.001)$ and intra-aortic balloon pump support $(P=.0488)$ and to experience intraoperative complications $(P=.0024)$.

Differences in postoperative characteristics between patients with and without excessive postoperative hemorrhage are shown in Table 3. Excessive postoperative hemorrhage was significantly associated with postoperative complications, including stroke $(P=.0002)$, low cardiac output $(P=.0240)$, pleural effusion $(P<.0001)$, postoperative pericardial tamponade $(P=.0013)$, and coagulopathy $(P<.0001)$. Patients with excessive postoperative hemorrhage were also significantly more likely to require prolonged ventilation after surgery $(P<.0001)$, re-exploration for bleeding $(P<.0001)$ and other causes $(P=.0075)$, 
TABLE 1. Preoperative characteristics of the patient cohort

\begin{tabular}{|c|c|c|c|c|}
\hline Variable & Total cohort $(n=1188)$ & No bleeding $(n=1112)$ & Bleeding $(n=76)$ & $P$ value, bleeding vs no bleeding \\
\hline All patients (n, \%) & 1,188 & 1,112 & $76(6.4 \%)$ & - \\
\hline Mean age, y (mean \pm SD) & $67.2( \pm 10.8)$ & $67.2( \pm 10.8)$ & $66.9( \pm 12.1)$ & .4950 \\
\hline Male sex $(n, \%)$ & $865(72.8 \%)$ & $803(72.2 \%)$ & $62(81.6 \%)$ & .0710 \\
\hline Mean BMI (mean $\pm \mathrm{SD})$ & $27.6( \pm 4.9)$ & $27.6( \pm 4.9)$ & $27.1( \pm 4.9)$ & .347 \\
\hline \multicolumn{5}{|l|}{ Admitting diagnosis (n, \%) } \\
\hline Unstable angina & $79(6.6 \%)$ & $75(6.7 \%)$ & $4(5.3 \%)$ & .6576 \\
\hline Acute myocardial infarction & $583(49.1 \%)$ & $551(49.6 \%)$ & $32(42.1 \%)$ & .2119 \\
\hline Valve disorder & $290(24.4 \%)$ & $270(36.8 \%)$ & $20(26.3 \%)$ & .6800 \\
\hline Other underlying disorder & $236(19.9 \%)$ & $216(19.7 \%)$ & $20(26.3 \%)$ & .1560 \\
\hline $\begin{array}{l}\text { Preoperative antithrombotics } \\
\text { (aspirin and clopidogrel) }\end{array}$ & $663(55.8 \%)$ & $623(56.0 \%)$ & $40(52.6 \%)$ & .5656 \\
\hline Preoperative anticoagulants (n, \%) & $263(22.1 \%)$ & $246(22.1 \%)$ & $17(22.4 \%)$ & .9426 \\
\hline IV nitrate $(\mathrm{n}, \%)$ & $55(4.6 \%)$ & $52(4.7 \%)$ & $3(3.9 \%)$ & .8232 \\
\hline IV inotrope (n, \%) & $22(1.9 \%)$ & $19(1.7 \%)$ & $3(3.9 \%)$ & .2087 \\
\hline Preoperative HCT (mean \pm SD) & $40.0( \pm 5.14)$ & $40.1( \pm 5.12)$ & $39.1( \pm 5.2)$ & .1083 \\
\hline Preoperative renal dysfunction (n, \%) & $302(25.4 \%)$ & $274(24.6 \%)$ & $28(36.8 \%)$ & .0229 \\
\hline Preoperative creatinine $(\mathrm{mg} / \mathrm{dL})$ & $1.15( \pm 0.6)$ & $1.13( \pm 0.6)$ & $1.3( \pm 0.6)$ & .013 \\
\hline \multicolumn{5}{|l|}{ Comorbidities (n, \%) } \\
\hline Liver disease & $61(5.1 \%)$ & $53(4.8 \%)$ & $8(10.5 \%)$ & .0485 \\
\hline GI disease & $68(5.7 \%)$ & $65(5.8 \%)$ & $3(3.9 \%)$ & .5269 \\
\hline Endocrine disease & $85(7.2 \%)$ & $76(6.8 \%)$ & $9(11.8 \%)$ & .1243 \\
\hline Malignancy & $35(2.9 \%)$ & $33(3.0 \%)$ & $2(2.6 \%)$ & .9406 \\
\hline Other & $334(28.1 \%)$ & $317(28.5 \%$ & $17(22.4 \%)$ & .2510 \\
\hline Acute infections & $83(7 \%)$ & $78(7.0 \%)$ & $5(6.6 \%)$ & .9316 \\
\hline Preoperative coagulopathy & $17(1.4 \%)$ & $13(1.2 \%)$ & $4(5.3 \%)$ & .0207 \\
\hline Previous OR (n, \%) & $87(7.3 \%)$ & $77(6.9 \%)$ & $10(13.2 \%)$ & .0631 \\
\hline \multicolumn{5}{|l|}{ Urgency $(n, \%)$} \\
\hline Elective & $450(37.9 \%)$ & $431(38.8 \%)$ & $19(25.0 \%)$ & .0152 \\
\hline Urgent & $485(40.8 \%)$ & $452(40.6 \%)$ & $33(43.4 \%)$ & .6333 \\
\hline Emergent & $241(20.3 \%)$ & $220(19.8 \%)$ & $21(27.6 \%)$ & .1107 \\
\hline Emergency/resuscitation & $12(1.0 \%)$ & $9(0.8 \%)$ & $3(3.9 \%)$ & .0416 \\
\hline
\end{tabular}

$B M I$, Body mass index; $C A B G$, coronary artery bypass graft; $H C T$, hematocrit; $I V$, intravenous; $G I$, gastrointestinal; $O R$, operations; $S D$, standard deviation.

transfusion of all blood products $(P<.0001)$, stay in the ICU for more than 72 hours $(P<.0001)$, and more manpower while in the ICU as measured by the TISS-28 score $(P<$ $.0001)$. In total, $22.4 \%$ of the patients with excessive postoperative hemorrhage were dead at 30 days after cardiac surgery, which was significantly higher than the 5.5\% mortality rate observed in patients without excessive hemorrhage $(P<.0001)$.

Univariate analysis of the key cost drivers in cardiac surgery revealed significantly higher costs in patients with excessive postoperative hemorrhage (Table 4). The cost of
ICU stay dominated overall costs $(51 \%)$, followed by the cost of manpower requirements (TISS-28 score) (28\%), surgery $(27 \%)$, and length of stay in general ward $(10 \%)$. The cost of reexploration $(3 \%)$ and blood transfusion (4\%) contributed little to the overall hospital costs. Without adjustment for potential confounding factors, the average hospital costs of patients with and without excessive postoperative hemorrhage were $€ 15,404( \pm 8986)$ and $€ 8027$ ( \pm 7557 ), respectively. Adjustment for relevant confounders in multivariate analysis indicated a significant incremental cost of excessive postoperative hemorrhage of $€ 6251$

TABLE 2. Intraoperative characteristics of patient cohort

\begin{tabular}{lcccc}
\hline \multicolumn{1}{c}{ Surgery-related covariates } & Total cohort $(\mathbf{n}=\mathbf{1 1 8 8})$ & No bleeding $(\mathbf{n}=\mathbf{1 1 1 2})$ & Bleeding $(\mathbf{n}=\mathbf{7 6})$ & $\boldsymbol{P}$ value, bleeding vs no bleeding \\
\hline Surgery time $(\mathrm{min})$ & $172.8( \pm 50.2)$ & $170.6( \pm 46.2)$ & $205.2( \pm 84.7)$ & .0012 \\
CPB duration $(\mathrm{min})$ & $78.3( \pm 33.3)$ & $77.1( \pm 31.5)$ & $96.3( \pm 50.8)$ & .0015 \\
Body temperature & $34.8( \pm 2.9)$ & $34.9( \pm 2.8)$ & $33.8( \pm 3.5)$ & .0009 \\
Use of IABP & $40(3.4 \%)$ & $34(3.1 \%)$ & $6(7.9 \%)$ & .0488 \\
Any intraoperative complications* & $38(3.2 \%)$ & $30(2.7 \%)$ & $8(10.5 \%)$ & .0024 \\
Other intraoperative complications & $20(1.7 \%)$ & $16(1.4 \%)$ & $4(5.3 \%)$ & .0410 \\
\hline
\end{tabular}

$\overline{C P B}$, Cardiopulmonary bypass; $I A B P$, intra-aortic balloon pump; $E C M O$, extracorporeal membrane oxygenation. *Intraoperative complications included low cardiac output, hypoxemia, and other intraoperative complications. 
TABLE 3. Postoperative characteristics of patient cohort

\begin{tabular}{|c|c|c|c|c|}
\hline Variable & Total cohort $(n=1188)$ & No bleeding $(n=1112)$ & Bleeding $(n=76)$ & $P$ value, bleeding vs no bleeding \\
\hline Postoperative complications & $75(6.3 \%)$ & $60(5.4 \%)$ & $15(19.7 \%)$ & $<.0001$ \\
\hline Stroke & $58(4.9 \%)$ & $46(4.1 \%)$ & $12(15.8 \%)$ & .0002 \\
\hline Low cardiac output & $65(5.5 \%)$ & $54(4.9 \%)$ & $11(14.5 \%)$ & .0240 \\
\hline Pleural effusion & $106(8.9 \%)$ & $93(8.4 \%)$ & $26(34.2 \%)$ & $<.0001$ \\
\hline Tamponade & $43(3.6 \%)$ & $34(3.1 \%)$ & $9(11.8 \%)$ & .0013 \\
\hline Coagulopathy & $16(1.3 \%)$ & $7(0.6 \%)$ & $9(11.8 \%)$ & $<.0001$ \\
\hline \multicolumn{5}{|l|}{ Postoperative ventilation } \\
\hline$>24 \mathrm{~h}$ & $147(12.4 \%)$ & $120(10.8 \%)$ & $27(35.5 \%)$ & $<.0001$ \\
\hline Hemofiltration & $188(15.8 \%)$ & $165(14.8 \%)$ & $23(30.3 \%)$ & .001 \\
\hline Reexploration & $84(7.1 \%)$ & $38(3.4 \%)$ & $45(59.2 \%)$ & \\
\hline For bleeding & $47(4.0 \%)$ & $9(0.8 \%)$ & $38(50 \%)$ & $<.0001$ \\
\hline For other causes & $37(3.0 \%)$ & $29(2.6 \%)$ & $7(9.2 \%)$ & .0075 \\
\hline $\begin{array}{l}\text { Postoperative blood } \\
\text { transfusions }\end{array}$ & $463(39.0 \%)$ & $388(34.9 \%)$ & $64(84.2 \%)$ & $<.0001$ \\
\hline $\mathrm{RBC}$ & $452(38.0 \%)$ & $388(34.9 \%)$ & $64(84.2 \%)$ & $<.0001$ \\
\hline FFP & $95(8.0 \%)$ & $56(5.0 \%)$ & $39(51.3 \%)$ & $<.0001$ \\
\hline Platelets & $39(3.3 \%)$ & $19(1.7 \%)$ & $19(25.0 \%)$ & $<.0001$ \\
\hline Units of RBC transfused & $1.1( \pm 2.3)$ & $0.9( \pm 1.9)$ & $4.5( \pm 3.8)$ & $<.0001$ \\
\hline Units FFP transfused & $0.5( \pm 2.2)$ & $0.3( \pm 1.6)$ & $4.1( \pm 5.2)$ & $<.0001$ \\
\hline Mean postoperative blood loss & $549( \pm 941)$ & $472( \pm 873)$ & $1,669( \pm 1170)$ & $<.0001$ \\
\hline \multicolumn{5}{|l|}{ LOS ICU } \\
\hline$>72 \mathrm{~h}(\mathrm{n}, \%)$ & $290(24.4 \%)$ & $251(22.6 \%)$ & $39(51.3 \%)$ & $<.0001$ \\
\hline Total & $4.1( \pm 4.7)$ & $3.1( \pm 5.0)$ & $5.7( \pm 5.3)$ & $<.0001$ \\
\hline TISS-28 & $66.9( \pm 69.5)$ & $44.7( \pm 52.8)$ & $85.9( \pm 76.5)$ & $<.0001$ \\
\hline Mortality & $72(6.1 \%)$ & $56(5.0 \%)$ & $16(21.1 \%)$ & $<.0001$ \\
\hline 30-day mortality & $78(6.6 \%)$ & $61(5.5 \%)$ & $17(22.4 \%)$ & $<.0001$ \\
\hline
\end{tabular}

$R B C$, Red blood cell; FFP, fresh frozen plasma; $I C U$, intensive care unit; $L O S$, length of stay; TISS-28, Therapeutic Intervention Scoring System.

(95\% confidence interval, 4594-7909; Table 5). Using this adjusted estimate, the average hospital cost of patients with excessive postoperative hemorrhage was $€ 14,279$, all else equal. In addition to postoperative hemorrhage, the multivariate analysis also indicated that preoperative inotrope use $(P=.000)$, preoperative renal dysfunction $(P=.000)$, any infection $(P=.000)$, previous operation $(P=.0269)$, elective $(P=.0052)$ and urgent procedures $(P=.000)$ were significant independent determinants of hospital costs.

\section{DISCUSSION}

The objective of this study was to quantify the incremental costs of excessive postoperative hemorrhage in cardiac surgery. We found that patients with excessive postoperative hemorrhage are significantly more likely to require prolonged ventilation after surgery, reexploration for bleeding and other causes, transfusion of all blood products, stay in the ICU for more than 72 hours, and more manpower while in the ICU as measured by the TISS-28 score. Adjusted for potential confounders, the higher resource requirements of patients with excessive postoperative hemorrhage resulted in significantly higher average hospital costs compared with patients without postoperative hemorrhage.

Our results compare well with those published by Herwaldt and colleagues ${ }^{7,8}$ despite differences in the definition of excessive postoperative hemorrhage. In their case-control

TABLE 4. Univariate analysis of hospital cost $(€)$ for cardiac surgery: effect of postoperative hemorrhage

\begin{tabular}{|c|c|c|c|c|}
\hline Cost components & All patients $(\mathrm{n}=1188)$ & No bleeding $(\mathrm{n}=1112)$ & Bleeding $(\mathbf{n}=76)$ & $P$ value \\
\hline Surgery-related* $($ mean $\pm \mathrm{SD})$ & $2304( \pm 669)$ & $2274( \pm 615)$ & $4018( \pm 1753)$ & $<.0001$ \\
\hline Postoperative complications $\dagger$ (mean $\pm \mathrm{SD}$ ) & $208( \pm 848)$ & $178( \pm 785)$ & $652( \pm 1429)$ & $<.0001$ \\
\hline Reexploration for bleeding (mean $\pm \mathrm{SD}$ ) & $230( \pm 842)$ & $112( \pm 600)$ & $1956( \pm 1635)$ & $<.0001$ \\
\hline Cost of blood products (mean \pm SD) & $134( \pm 346)$ & $93( \pm 257)$ & $732( \pm 730)$ & $<.0001$ \\
\hline Cost of total ICU stay (mean \pm SD) & $4370( \pm 6779)$ & $4150( \pm 6699)$ & $7582( \pm 7172)$ & $<.0001$ \\
\hline Cost by TISS- 28 score & $2407( \pm 2502)$ & $1609( \pm 1902)$ & $3095( \pm 2754)$ & $<.0001$ \\
\hline Cost of ward stay & $876( \pm 661)$ & $877( \pm 640)$ & $859( \pm 928)$ & .0461 \\
\hline Total cost $($ mean $\pm \mathrm{SD}) \ddagger$ & $8499( \pm 7862)$ & $8027( \pm 7557)$ & $15,404( \pm 8986)$ & $<.0001$ \\
\hline
\end{tabular}

*Based on surgery time and CPB time, postoperative complications include cost for myocardial infarction and stroke. $\dagger$ Intraoperative complications included low cardiac output, hypoxemia, and other intraoperative complications. ‡Total cost should not be summed, represents mean total cost of cost components only. 
TABLE 5. Multivariate analysis of hospital costs $(€)$ for cardiac surgery

\begin{tabular}{|c|c|c|c|c|c|}
\hline & Incremental cost & Standard error & $t$ value & $P$ value & $\mathbf{9 5} \%$ confidence interval \\
\hline Constant* & 8027.51 & 1.8696606 & 4293.565 & .000 & $8023.84-8031.17$ \\
\hline Age & 11.33 & 20.415367 & 0.555 & .579 & $-28.69-51.34$ \\
\hline Male & 995.74 & 478.70688 & 2.08 & .0375 & $57.48-1934.01$ \\
\hline BMI & 69.73 & 41.987478 & 1.661 & .0968 & $-12.57-152.03$ \\
\hline \multicolumn{6}{|l|}{ Admitting diagnosis } \\
\hline MI & -348.99 & 849.89334 & -0.411 & .6813 & $-2014.78-1316.80$ \\
\hline Valve disorder & 57.72 & 906.06157 & 0.064 & .9492 & $-1718.16-1833.60$ \\
\hline Other & 202.35 & 934.87075 & 0.216 & .8286 & $-1630.00-2034.70$ \\
\hline Antithrombotics use & 9.60 & 8.3284475 & 1.153 & .2491 & $-6.72-25.92$ \\
\hline Preoperative anticoagulants & -6.62 & 4.1160559 & -1.607 & .108 & $-14.68-1.45$ \\
\hline IV nitrate & -201.64 & 1003.816 & -0.201 & .8408 & $-2169.12-1765.84$ \\
\hline IV inotrope & $11,737.56$ & 1630.3749 & 7.199 & .000 & $8542.02-14,933.09$ \\
\hline HCT & -0.45 & 1.577093 & -0.284 & .7765 & $-3.54-2.64$ \\
\hline Renal dysfunction & 3078.31 & 508.93187 & 6.049 & .000 & $2080.81-4075.82$ \\
\hline Creatinine & 3.42 & 7.2556871 & 0.471 & .6376 & $-10.80-17.64$ \\
\hline \multicolumn{6}{|l|}{ Comorbidities } \\
\hline Liver disease & 0.98 & 3.5436956 & 0.275 & .783 & $-5.97-7.92$ \\
\hline GI disease & 8.43 & 8.2886632 & 1.017 & .3092 & $-7.82-24.67$ \\
\hline Endocrine disease & -1.30 & 5.0370064 & -0.258 & .7964 & $-11.17-8.57$ \\
\hline Malignancy & -54.66 & 1245.7818 & -0.044 & .965 & $-2496.40-2387.07$ \\
\hline Other comorbidity & -0.21 & 4.0891052 & -0.05 & .96 & $-8.22-7.81$ \\
\hline Any infection & 3492.79 & 831.63853 & 4.2 & .000 & $1862.78-5122.80$ \\
\hline Coagulopathy & -2.25 & 2.367213 & -0.951 & .3417 & $-6.89-2.39$ \\
\hline Previous operation & 1781.62 & 804.87552 & 2.214 & .0269 & $204.06-3359.17$ \\
\hline Elective & -1317.33 & 471.63121 & -2.793 & .0052 & $-2241.73-392.93$ \\
\hline Urgent & 2376.88 & 577.36643 & 4.117 & .000 & $1245.24-3508.52$ \\
\hline Emergent & -2047.63 & 2196.2459 & -0.932 & .3512 & $-6352.27-2257.01$ \\
\hline Bleeding $\dagger$ & 6251.38 & 845.60114 & 7.393 & .000 & 4594.00-7908.76 \\
\hline
\end{tabular}

BMI, Body mass index; $M I$, myocardial infarction; $I V$, intravenous; $H C T$, hematocrit; $G I$, gastrointestinal. *Average cost for patients without postoperative hemorrhage, all else equal. †Incremental cost for patients with postoperative hemorrhage.

studies, excessive postoperative hemorrhage was defined by either a surrogate for bleeding (reoperation for bleeding regardless of the amount of blood lost in chest tubes) or by postoperative chest tube drainage greater than $800 \mathrm{~mL}$ during a 4-hour period. In the first study, ${ }^{7}$ the authors found patients with postoperative chest tube drainage greater than $800 \mathrm{~mL}$ to have significantly more blood transfusions and longer hospital stays than controls. The unadjusted mean difference in hospital costs was $\$ 11,266$ (or $€ 7702$ when using current exchange rate), which is very close to the unadjusted cost difference of $€ 7377$ observed in our study. In the second study, using a mixture of patients identified with postoperative hemorrhage due to the surgery or volume criteria, the mean difference in hospital costs was substantially smaller (\$2945), yet this is likely explained by the difference in eligibility criteria.

In our study, we found the average incremental (extra) cost of excessive postoperative hemorrhage to be $€ 6251$ per patient. Although this amount may not seem excessive on a larger scale of health care spending, it is important to note that this cost estimate only relates to the resources required during the initial hospitalization. The cost of follow-up care (inpatient and outpatient) may be significant, in particular in regards to postoperative complications such as AMI and stroke. ${ }^{15-17}$ Indeed, the long-term health care costs associated with AMI and stroke may represent the majority of the life-costs in AMI and stroke survivors. In addition, there are the indirect costs of excessive postoperative hemorrhage in terms of foregone productivity attributable to premature mortality and morbidity. In gauging the potential of new clinical interventions to address the cost of excessive postoperative hemorrhage, the perspective of the assessor is clearly paramount (eg, hospital, insurance company, or government). However, when the cost of excessive postoperative hemorrhage is considered from a national long-term perspective, both the direct and indirect costs of the complication should clearly be evaluated.

The etiology of excessive postoperative hemorrhage in cardiac surgery is multifactorial and may be related to medications, history of preexisting coagulopathy, surgical procedure, and other unrecognized factors. ${ }^{10}$ An important aspect of addressing excessive hemorrhage relates to preoperatively identifying patients at risk during or after surgery. In our study, we found patients with excessive postoperative hemorrhage to be more likely to have preoperative renal dysfunction, liver disease, and coagulopathy; to need 
emergency/resuscitation surgery; and to require longer surgery time, including time spent on the CPB. In other studies, increased age, nonelective surgery, low body surface area, prolonged CPB time ( $>150$ minutes), combined intracardiac and coronary bypass graft surgery, number of bypass grafts $(\geq 5)$, reoperative surgery, and preoperative antiplatelet agents have been consistently identified as risk factors for postoperative hemorrhage. ${ }^{4,18,19}$ Though more research on the risk factors for excessive postoperative hemorrhage is needed, ${ }^{8}$ it is clear that, from a cost-effectiveness perspective, clinical interventions that can either prevent or effectively address postoperative hemorrhage are likely to be cost-effective. In our study, we observed a mortality rate of $22.4 \%$ in patients with excessive postoperative hemorrhage compared with $5.5 \%$ in patients without this complication. At an average incremental cost of $€ 6251$, the difference in survival implies an average $€ 36,771$ per life lost as a result of this complication. In other words, patients with excessive postoperative hemorrhage are more expensive and more likely to die than those without excessive postoperative hemorrhage. Even without taking the longterm costs (direct or indirect) of excessive postoperative hemorrhage into account, there seems ample economic potential for addressing this critical clinical complication.

Our study has a number of limitations. First, our estimate of the incremental costs of excessive postoperative hemorrhage depends in part on the unit cost associated with the extra resources required to treat this complication. Unit costs are inherently idiosyncratic for the health care system in which they are retrieved, and hence it is questionable to what extent our estimation can be generalized to other health care systems outside of Germany. Second, we did not include the long-term costs (direct or indirect) associated with excessive postoperative hemorrhage. In patients with thromboembolic complications such as AMI and stroke, these costs are likely to be substantial. Additionally, the high mortality rate associated with excessive postoperative hemorrhage indicates that there are substantial societal losses associated with this complication relating to lost productivity. Future research should aim to quantify the long-term economic implications of excessive postoperative hemorrhage and its associated clinical outcomes. Third, our assessment did not take into account the impact of excessive postoperative hemorrhage on quality of life. For the patients left with significant functional disabilities due to stroke, the nonmonetary cost to survivors and their family can be substantial.

\section{CONCLUSIONS}

We find the average hospital costs of excessive postoperative hemorrhage in cardiac surgery to be substantial and associated with a significant risk of postoperative complications and death. Clinical interventions that can effectively prevent or address excessive postoperative hemorrhage in cardiac surgery are likely to have substantial cost-effectiveness potential.

\section{References}

1. Bucerius J, Gummert JF, Borger MA, Walther T, Doll N, Onnasch JF, et al. Stroke after cardiac surgery: a risk factor analysis of 16,184 consecutive adult patients. Ann Thorac Surg. 2003;75:472-8.

2. Hall TS, Brevetti GR, Skoultchi AJ, Sines JC, Gregory P, Spotnitz AJ. Re-exploration for hemorrhage following open heart surgery differentiation on the causes of bleeding and the impact on patient outcomes. Ann Thorac Cardiovasc Surg. 2001;7:352-7.

3. Moulton MJ, Creswell LL, Mackey ME, Cox JL, Rosenbloom M. Reexploration for bleeding is a risk factor for adverse outcomes after cardiac operations. J Thorac Cardiovasc Surg. 1996;111:1037-46.

4. Dacey LJ, Munoz JJ, Baribeau YR, Johnson ER, Lahey SJ, Leavitt BJ, et al. Reexploration for hemorrhage following coronary artery bypass grafting: incidence and risk factors. Northern New England Cardiovascular Disease Study Group. Arch Surg. 1998;133:442-7.

5. Karkouti K, Wijeysundera DN, Yau TM, Beattie WS, Abdelnaem E, McCluskey SA, et al. The independent association of massive blood loss with mortality in cardiac surgery. Transfusion. 2004;44:1453-62.

6. Murphy GJ, Reeves BC, Rogers CA, Rizvi SI, Culliford L, Angelini GD. Increased mortality, postoperative morbidity, and cost after red blood cell transfusion in patients having cardiac surgery. Circulation. 2007;116:2544-52.

7. Herwaldt LA, Swartzendruber SK, Zimmerman MB, Scholz DA, Franklin JA, Caldarone CA. Hemorrhage after coronary artery bypass graft procedures. Infect Control Hosp Epidemiol. 2003;24:44-50.

8. Herwaldt LA, Swartzendruber SK, Edmond MB, et al. The epidemiology of hemorrhage related to cardiothoracic operations. Infect Control Hosp Epidemiol. 1998;19:9-16

9. Daly DJ, Myles PS, Smith JA, Knight JL, Clavisi O, Bain DL, et al. Anticoagulation, bleeding and blood transfusion practices in Australasian cardiac surgical practice. Anaesth Intensive Care. 2007;35:760-8

10. Whitlock R, Crowther MA, Ng HJ. Bleeding in cardiac surgery: its prevention and treatment-an evidence-based review. Crit Care Clin. 2005;21:589-610.

11. Charalambous CP, Zipitis CS, Keenan DJ. Chest reexploration in the intensive care unit after cardiac surgery: a safe alternative to returning to the operating theater. Ann Thorac Surg. 2006;81:191-4.

12. Koch CG, Li L, Duncan AI, Mihaljevic T, Cosgrove DM, Loop FD, Starr NJ, Blackstone EH. Morbidity and mortality risk associated with red blood cell and blood-component transfusion in isolated coronary artery bypass grafting. Crit Care Med. 2006;34:1608-16.

13. Engoren MC, Habib RH, Zacharias A, Schwann TA, Riordan CJ, Durham SJ. Effect of blood transfusion on long-term survival after cardiac operation. Ann Thorac Surg. 2002;74:1180-6.

14. BQS Bundesgeschäftsstelle Qualitätssicherung. BQS-Qualitätsreport 2006. Available at: http://www.bqs-qualitaetsreport.de. Last accessed February 2008.

15. Lee WC, Christensen MC, Joshi A, Pashos C. Long-term cost of stroke sub-types among Medicare beneficiaries. Cerebrovasc Dis. 2007;23:57-65.

16. Sloss EM, Wickstrom SL, McCaffrey DF, Garber S, Rector TS, Levin RA, et al. Direct medical costs attributable to acute myocardial infarction and ischemic stroke in cohorts with atherosclerotic conditions. Cerebrovasc Dis. 2004;18:8-15.

17. Navarrete P, Hart WM, Lopez J, Christensen MC. The societal costs of intracerebral haemorrhage in Spain. Eur J Neurol. 2007;14:556-62.

18. Karthik S, Grayson AD, McCarron EE, Pullan DM, Desmond MJ. Reexploration for bleeding after coronary artery bypass surgery: risk factors, outcomes, and the effect of time delay. Ann Thorac Surg. 2004;78:527-34.

19. Sellman M, Intonti MA, Ivert T. Reoperations for bleeding after coronary artery bypass procedures during 25 years. Eur J Cardiothorac Surg. 1997;11:521-7.

20. Herzchirurgie, Bad Krozingen. Herzchirurgie, Bad Krozingen-DRG-Entgelttarif 2007 für Krankenhäuser im Anwendungsbereich des KHEntG. Bad Krozingen: Herzzentrum; 2007. p. 2008

21. Harig F, Rösch J, Mahmoud FO, Weyand M, Feyrer R. Cost effectiveness of routine antifibrinolytic therapy in cardiac surgery: tranexamic acid shows equivalent effects and reduces costs compared to aprotinin [abstract]. Thorac Cardiovasc Surg. 2007;55.

22. Graf J, Graf C, Janssens U. Analysis of resource use and cost-generating factors in a German medical intensive care unit employing the Therapeutic Intervention Scoring System (TISS-28). Intensive Care Med. 2002;28:324-31. 
APPENDIX 1. Unit cost by hospital resource

\begin{tabular}{|c|c|c|}
\hline Cost component & Cost $(€)$ & Source/reference \\
\hline \multicolumn{3}{|l|}{$\begin{array}{l}\text { Surgery } \\
\end{array}$} \\
\hline Surgery time (per minute) & 13.33 & OP Management, 2007 (€800 per hour) \\
\hline Hemofiltration (run time per day) & 943.00 & Herzchirurgie, Bad Krozingen, $2007^{20}$ \\
\hline ECMO & 5736.00 & Herzchirurgie, Bad Krozingen, $2007^{20}$ \\
\hline IABP & 1283.00 & Herzchirurgie, Bad Krozingen, $2007^{20}$ \\
\hline \multicolumn{3}{|l|}{ Recovery } \\
\hline Cost for reexploration & 3305.00 & Herzchirurgie, Bad Krozingen, $2007^{20}$ \\
\hline Transfusion of RBC (cost per unit) & 75.00 & Harig et al., $2007^{21}$ \\
\hline Transfusion of FFP (cost per unit) & 67.00 & Harig et al., $2007^{21}$ \\
\hline Transfusion of platelets (cost per unit) & 467.00 & Harig et al., $2007^{21}$ \\
\hline ICU cost per day $(24 \mathrm{~h})$ & 1334.00 & Graf et al., $2002^{22}$ \\
\hline Cost per ward day & 62.00 & Herzchirurgie, Bad Krozingen, $2007^{20}$ \\
\hline TISS-28 (cost per point/score) & 36.00 & Graf et al., $2002^{22}$ \\
\hline
\end{tabular}

$E C M O$, Extracorporeal membrane oxygenation; $I A B P$, intra-aortic balloon pump; $R B C$, red blood cells; $F F P$, fresh frozen platelets; $I C U$, intensive care unit; $T I S S-28$, Therapeutic Intervention Scoring System; $A M I$, acute myocardial infarction. 